\title{
Effect of Green, Tulsi, and Areca Teas on the Color Stability of Two Composite Resin Materials - an in vitro Spectrophotometric Analysis
}

This article was published in the following Dove Press journal: Clinical, Cosmetic and Investigational Dentistry

\author{
Akshata Patil (D) \\ Vidya-Saraswathi Muliya (D) \\ Kalyana-Chakravarthy \\ Pentapati iD ${ }^{2}$ \\ Shobha Kamath iD $^{3}$ \\ 'Department of Conservative Dentistry \\ and Endodontics, Manipal College of \\ Dental Sciences, Manipal, Manipal \\ Academy of Higher Education, Manipal, \\ Karnataka, India; ${ }^{2}$ Department of Public \\ Health Dentistry, Manipal College of \\ Dental Sciences, Manipal, Manipal \\ Academy of Higher Education, Manipal, \\ Karnataka, India; ${ }^{3}$ Department of \\ Biochemistry, Kasturba Medical College, \\ Manipal, Manipal Academy of Higher \\ Education, Manipal, Karnataka, India
}

Objective: To compare the effect of Green, Tulsi, and Areca teas on the color stability of two composite materials on the 30th and 60th days.

Materials and Methods: Two light cure composite restorative materials, Brilliant EverGlow (Group 1) and Brilliant NG, (Group 2) with different resin and filler characteristics were selected. The test solutions selected were Green tea, Tulsi tea, Areca tea, and artificial saliva (control group). In total, 104-disc shaped specimens were fabricated using a custom made brass mold as per the manufacturer instructions. All specimens were put in storage for rehydration and complete polymerization at $37^{\circ} \mathrm{C}$ in distilled water for 24 hours. Specimens of each composite material were randomly divided into four subgroups of 13 samples. Tea solutions were freshly prepared, and specimens were immersed in the respective solutions every day for 15 minutes for 60 days. Specimens were stored in artificial saliva after the immersion regimen. The color evaluation was done before immersion, on the 30th and 60th day, using a digital reflectance spectrophotometer.

Results: At 30 days, Group 1 specimens immersed in Areca and Green teas showed significantly higher mean values than those in control and Tulsi tea. At 60 days in Group 1, specimens in Areca tea showed significantly higher mean value, followed by Green tea, Tulsi tea, and control. At 30 and 60 days in group 2, specimens in control had significantly lower mean values than other tea preparations. Group 1 showed a higher mean difference in $\Delta \mathrm{E}$ than Group 2 specimens immersed in Green and Areca teas at 30 days $(\mathrm{P}=0.001$ and $0.001)$ and 60 days $(\mathrm{P}=0.001$ and $<0.001)$, respectively.

Conclusion: All herbal tea preparations exhibited staining potential, which increased over time, and Areca tea showed the highest staining potential. Understanding the staining potential of newer tea preparations on recent composite materials helps the clinician to choose the right restorative materials.

Keywords: Areca tea, composites, discoloration, green tea, stain, tulsi tea

\section{Introduction}

Discoloration of composite resin may occur due to several extrinsic and intrinsic factors. Extrinsic factors include plaque, stains and absorption of colorants from exogenous sources. ${ }^{1}$ Intrinsic factors involve reactions in the composite matrix, which can be triggered by physical characteristics such as ultraviolet light, heat, and humid conditions. The magnitude of intrinsic discoloration also depends on the dimension of filler particles and the type of photoinitiator. ${ }^{2}$ Although extrinsic discoloration due to stains can be managed by polishing the existing restoration
Correspondence: Vidya-Saraswathi Muliya Department of Conservative Dentistry and Endodontics, Manipal College of

Dental Sciences, Manipal, Manipal Academy of Higher Education, Manipal

576 104, Karnataka, India

Tel +9l-984-574-2360

Email vidya.saraswathi@manipal.edu 
to a certain extent, intrinsic discoloration may mandate a replacement. The serviceability of the restoration is based on the clinician's ability to restore the esthetics by polishing the existing restoration.

Tea is a popular and favorite beverage across the world. There is an increased awareness of diet, and health consciousness, which has led to a gradual shift of consumer preference from traditional tea to tea with health benefits like Green Tea, Tulsi Tea, and Areca tea. ${ }^{3}$ Green Tea has antioxidants and nutrients that have powerful effects on the body. ${ }^{4}$ Tulsi (Ocimum tenuiflorum) of the mint family, often referred to as "The Queen of Herbs," makes a nourishing herbal tea with a vast array of health benefits. ${ }^{5}$ Areca tea, derived from extracts of Areca nut (Areca Catechu) of the family Arecaceae, claims to possess anti-ulcer, anti-aging, hypo-lipidemic, anti-diabetic properties and claims to enhance digestion and metabolism. ${ }^{6}$

Brilliant EverGlow and Brilliant NG are newer composites used as esthetic restorative materials. Brilliant EverGlow is a universal submicron hybrid, and Brilliant NG is a universal nanohybrid composite material. These two composites have demonstrated superior esthetic properties compared to other restorative materials. ${ }^{7}$ Manufacturer of these two materials claim superior polishability, reduced shrinkage, and superior physical properties.

Studies have reported the discoloration of composite restorative materials by colored solutions such as tea, coffee, and other beverages. ${ }^{8}$ Tea contains large amounts of staining compounds, including tannins, theaflavins, thearubigins, which might stain more with a stronger brew. ${ }^{9}$ However, the staining potential of these newer beverages on teeth and composite restorations have not been studied.

We aimed to compare the effect of Green tea, Tulsi Tea, and Areca tea on the color stability of these two composite materials on the 30th and 60th days, using a spectrophotometer. Our null hypothesis was that there would be no significant difference in the staining potential of Green tea, Tulsi Tea, and Areca tea on these two composite materials.

\section{Materials and Methods}

\section{Specimen Preparation}

One hundred and four disc-shaped specimens of Group 1 (Brilliant EverGlow, Coltene/Whaledent, Altstatten Switzerland, Shade \# A2/B2 G27377) (n=52) and Group 2 (Brilliant NG, Coltene/Whaledent, Altstatten Switzerland, Shade \# A2/B2 1304738), ( $\mathrm{n}=52)$ composite material were fabricated using a custom made brass mold, with the dimension of $10 \mathrm{~mm}$ in diameter and $2 \mathrm{~mm}$ in thickness as recommended previously. ${ }^{10}$ The composition of the composites is detailed in Table 1.

The resin composites were placed in the mold and covered with mylar strip (Samit, India). Care was taken to prevent bubble formation. A flat surface was obtained by positioning a $1 \mathrm{~mm}$ thick glass slide over the mylar strip before curing with a light activating source (Bee Cool, Confident, India) with a light output of $500 \mathrm{~mW} /$ $\mathrm{cm}^{2}$ for 40 seconds. The distance from the light and the specimen was standardized by making the tip of the curing light touch the glass slab while curing every specimen.

All specimens were put in storage for rehydration and complete polymerization at $37^{\circ} \mathrm{C}$ in distilled water for 24 hours, following which a baseline color estimation was done on the top surface using a reflectance spectrophotometer. ${ }^{11}$

Specimens of Group 1 and 2 were randomly divided into four subgroups of 13 samples each, according to the test solutions used - artificial saliva (control) (Department of Biochemistry, Kasturba Medical College Manipal, Karnataka, India), Green tea (Lipton, Mumbai, Maharashtra, India), Tulsi tea (Organic India Pvt. Ltd., Lucknow, UP, India), and Areca tea (Green Remedies, Udupi, Karnataka, India).

\section{Stain Challenge}

Tea solutions were prepared by immersing two prefabricated instant preparation tea bags $(2 \mathrm{gm} \times 2)$ into $300 \mathrm{~mL}$ of boiling water for 3 minutes. ${ }^{12}$ After 3 minutes, the bags were discarded, and the tea solution was allowed to cool down for 5 minutes. The solutions were freshly prepared each day for 60 days.

Table I Characteristics of the Composite Resins Included in the Study

\begin{tabular}{|l|l|l|l|}
\hline Composite & Shade & Matrix & Filler Composition \\
\hline Brilliant NG & A2/B2 & BisGMA, BisEMA, TEGDMA & Nanohybrid filler $(0.02-2.5 \mu \mathrm{m}) 65$ vol\% (80 wt\%) \\
Brilliant EverGlow & A2/B2 & Methacrylates & Submicron Hybrid filler $(0.02-\mathrm{I} .5 \mu \mathrm{m}) 56$ vol\% (74 wt\%) \\
\hline
\end{tabular}




\section{Immersion Regimen}

The fabricated specimens were immersed in the respective solutions every day for 15 minutes. After the immersion regimen, specimens were stored in artificial saliva. This regimen was followed for 60 days. The color evaluation was done before immersion, on the 30th day and 60th day.

\section{Spectrophotometric Analysis}

Color change on the specimens was recorded using a digital reflectance spectrophotometer (X-rite i1PRO Spectrophotometer and Profile maker Pro 5.0.10 software). Color measurements were performed after drying each disc using blotting paper. Each disc was positioned on a white background to prevent potential absorption during color measurement. The active point of the spectrophotometer was placed at the center of the disc to take the reading. This was repeated thrice, and the subsequent average of the three readings was taken. The average of the three values of $\Delta \mathrm{E}^{*}$ was calculated and used for data analysis. $^{13}$

The color difference for each disc at baseline, 30 days, and 60 days was calculated using the following equation: ${ }^{14}$

$$
\Delta \mathrm{E} *=\left[(\Delta \mathrm{L} *)^{2}+(\Delta \mathrm{a} *)^{2}+(\Delta \mathrm{b} *)^{2}\right]^{1 / 2}
$$

\section{Statistical Analysis}

All the analyses were done using SPSS version 20 (IBM Corp. Released 2011. IBM SPSS Statistics for Windows, Version 20.0. Armonk, NY: IBM Corp.). A $p$-value of $<0.05$ was considered statistically significant. We checked the normality of the data with Kolmogorov-Smirnov test. We found data was non-normal at various levels of materials and the solution, while Q-Q plots showed that all the points were along the reference line. Hence, we performed
Mixed model ANOVA as it is a robust method. There were significant two- and three-way interactions, which can lead to misinterpretation. Therefore, we reported the results using the simple main effects. Intra-group comparison of mean $\triangle \mathrm{E}$ was made using repeated-measures ANOVA with post-hoc Bonferroni test. Comparison of mean difference in $\Delta \mathrm{E}$ among the four test solutions was made using Kruskal Wallis ANOVA with post-hoc Conover test. Comparisons of mean difference in $\Delta \mathrm{E}$ between the two types of composite materials were made using the MannWhitney $U$-test.

\section{Results}

The intra-group comparison showed that all the specimens in Groups 1 and 2 showed significant differences in the mean $\Delta \mathrm{E}$ from baseline through 60 days concerning various storage solutions (control, Green tea, Tulsi tea, and Areca tea). The post-hoc tests showed that across all the storage solutions, the mean $\Delta \mathrm{E}$ was significantly higher at 60 days and lowest at baseline in both Group 1 and 2 (Table 2). This suggested that all the storage solutions significantly increased the mean $\Delta \mathrm{E}$ over 60 days.

There were significant differences in the mean difference of $\Delta \mathrm{E}$ at $30(p<0.001)$ and 60 days $(p<0.001)$ in Group 1. At 30 days, specimens immersed in Areca tea and Green tea showed significantly higher mean values than specimens immersed in control and Tulsi tea. Also, specimens in control had lower mean values than all other tea preparations. At 60 days, specimens in Areca tea showed significantly higher mean value, followed by specimens in Green tea, Tulsi, and control.

There were significant differences in the mean difference of $\Delta \mathrm{E}$ at $30(p<0.001)$ and 60 days $(p<0.001)$ in Group 2. At 30 days, specimens in control had

Table 2 Intra-Group Comparison of the Mean $\Delta \mathrm{E}$ Values at Baseline, 30 and 60 Days

\begin{tabular}{|c|c|c|c|c|c|c|}
\hline Type of Composite & Test Solution & $\begin{array}{l}\Delta E \text { at Baseline } \\
\text { Mean ( } \pm S D)\end{array}$ & $\begin{array}{l}\Delta E \text { at } 30 \text { Days } \\
\text { Mean ( } \pm S D)\end{array}$ & $\begin{array}{l}\Delta \mathrm{E} \text { at } 60 \text { Days } \\
\text { Mean }( \pm \mathrm{SD})\end{array}$ & p-value & Post-Hoc Test \\
\hline $\begin{array}{l}\text { Group I } \\
\text { (Brilliant EverGlow) }\end{array}$ & $\begin{array}{l}\text { Artificial saliva } \\
\text { Green tea } \\
\text { Tulsi tea } \\
\text { Areca tea }\end{array}$ & $\begin{array}{l}27.78 \pm 1.79 \\
28.95 \pm 1.73 \\
28.25 \pm 1.74 \\
28.35 \pm 1.63\end{array}$ & $\begin{array}{l}29.73 \pm 0.56 \\
32.68 \pm 2.03 \\
29.75 \pm 2.25 \\
32.65 \pm 1.20\end{array}$ & $\begin{array}{l}29.14 \pm I .24 \\
33.75 \pm I .66 \\
30.93 \pm I .21 \\
35.20 \pm I .14\end{array}$ & $\begin{array}{l}<0.001 \\
<0.001 \\
<0.001 \\
<0.001\end{array}$ & $\begin{array}{l}B<30,60 \\
B<30<60 \\
B<60 \\
B<30<60\end{array}$ \\
\hline $\begin{array}{l}\text { Group } 2 \\
\text { (Brilliant NG) }\end{array}$ & $\begin{array}{l}\text { Artificial saliva } \\
\text { Green tea } \\
\text { Tulsi tea } \\
\text { Areca tea }\end{array}$ & $\begin{array}{l}30.28 \pm 1.36 \\
31.16 \pm 0.93 \\
30.68 \pm 0.53 \\
30.57 \pm 1.04\end{array}$ & $\begin{array}{l}30.85 \pm 1.26 \\
32.90 \pm 0.18 \\
32.42 \pm 0.57 \\
32.30 \pm 0.67\end{array}$ & $\begin{array}{l}31.08 \pm 1.10 \\
33.19 \pm .16 \\
33.15 \pm 0.81 \\
33.47 \pm 1.29\end{array}$ & $\begin{array}{l}<0.001 \\
<0.001 \\
<0.001 \\
<0.001\end{array}$ & $\begin{array}{l}B<30,60 \\
B<30<60 \\
B<30<60 \\
B<30<60\end{array}$ \\
\hline
\end{tabular}

Notes: Repeated Measures ANOVA with post-hoc Bonferroni test; B, baseline; 30, 30 days; 60, 60 days. 
significantly lower mean values than specimens immersed in all other tea preparations. Similar findings were seen at 60 days. Also, specimens immersed in Areca tea had a higher mean than Green tea (Table 3).

There was no significant difference in the mean difference in $\Delta \mathrm{E}$ between Groups 1 and 2 specimens immersed in control and Tulsi tea at 30 days $(\mathrm{P}=0.121$ and 0.34$)$ and 60 days $(\mathrm{P}=0.312$ and 0.588$)$ respectively. However, Group 1 showed a higher mean difference in $\Delta \mathrm{E}$ than Group 2 specimens immersed in Green tea and Areca tea at 30 days $(\mathrm{P}=0.001$ and 0.001$)$ and 60 days $(\mathrm{P}=0.001$ and $<0.001$ ) respectively (Table 3 ). It can be implied that the staining potential of Group 1 was higher than Group 2 for specimens immersed in Green tea and Areca tea.

\section{Discussion}

The present in vitro study was conducted to evaluate the staining potential of new herbal beverages on universal submicron hybrid composite (Brilliant EverGlow) and universal nanohybrid composite (Brilliant $\mathrm{NG}$ ) restorative materials. These composite resins were chosen as they showed better color stability. ${ }^{7}$

Visual or instrumental techniques can be employed for assessment of color stability. Since instrument readings obliterate the subjective color comparison interpretation, spectrophotometer and colorimeter were used to assess color changes in dental materials. Color discrepancies below the threshold of visual perception can be detected using Spectrophotometers. As CIEL *a*b* system shows minute color differences, it was chosen for measuring chromaticity. ${ }^{15}$ The use of the CIEL*a*b system and the associated color difference metrics has been formulated particularly to improve visual interpretation of colorimetric data and is swiftly growing into a useful, standardized technique for accurate analysis of $\Delta \mathrm{E}^{*}$ values. ${ }^{16}$

Lighting conditions will determine the accuracy of the measured color while measuring the reflective surfaces or objects. Since color differences were being tested, the choice of illuminant was not essential. However, in the current study, a standard illuminant (D65) was used. The color of the material is also affected by the thickness and smoothness of the specimen surface to a great extent. In the present study, all specimens were maintained at a uniform thickness of $2 \mathrm{~mm}$. Since the color variance estimate, $\left(\Delta \mathrm{E}^{*}\right)$ was calculated at 2-time intervals in a three-dimensional $\mathrm{L}^{*} \mathrm{a} * \mathrm{~b} *$ color space, the thickness of specimens was not much of an importance. ${ }^{15}$

A wide variety of test solutions or beverages like coffee, tea, cola, red wine, grape juice, orange juice, distilled water, chlorhexidine, and artificial saliva have been used in the past to evaluate the color stability of the dental restorative materials. ${ }^{2,17,18}$ Due to growing awareness in lifestyle modification and increased availability of over the counter herbal and alternative supplements, there is a shift from traditional beverages (tea and coffee) to healthier alternatives (Areca tea, Green tea, and Tulsi tea). Hence, our study evaluated the effect of these novel herbal teas on the color stability of composite restorative materials.

Numerous factors such as organic matrix form, particle size, degree of polymerization, time between restoration finishing and polishing, degree of smoothness, water sorption, type, and duration of contact with staining solution have a substantial role in the staining of the dental composite resins. ${ }^{19}$ Fonseca et al concluded that the type of monomer in a composite resin could have a potential effect

Table 3 Comparison of Mean Difference in $\Delta \mathrm{E}$ at 30 and 60 Days Among Different Solutions and Between the Groups

\begin{tabular}{|c|c|c|c|c|c|c|c|}
\hline \multicolumn{2}{|c|}{$\begin{array}{l}\text { Mean Difference with Respect to } \\
\text { Baseline } \Delta E\end{array}$} & Artificial Saliva [A] & $\begin{array}{l}\text { Green Tea } \\
\text { [B] }\end{array}$ & $\begin{array}{l}\text { Tulsi Tea } \\
\text { [C] }\end{array}$ & $\begin{array}{l}\text { Areca Tea } \\
\text { [D] }\end{array}$ & $p$-value ${ }^{\dagger}$ & Post-Hoc Test \\
\hline 30 days & $\begin{array}{l}\text { Group I } \\
\text { (Brilliant EverGlow) } \\
\text { Group } 2 \\
\text { (Brilliant NG) } \\
\text { p-value }{ }^{\ddagger}\end{array}$ & $\begin{array}{l}2.10 \pm 1.59 \\
0.60 \pm 0.29 \\
0.121\end{array}$ & $\begin{array}{l}3.73 \pm 2.09 \\
1.74 \pm 0.95 \\
0.005\end{array}$ & $\begin{array}{l}2.09 \pm 1.31 \\
1.74 \pm 1.05 \\
0.34\end{array}$ & $\begin{array}{l}4.31 \pm 1.63 \\
1.73 \pm 0.49 \\
0.001\end{array}$ & $\begin{array}{l}<0.001 \\
<0.001\end{array}$ & $\begin{array}{l}B, D>A, C \\
B, C, D>A\end{array}$ \\
\hline 60 days & $\begin{array}{l}\text { Group I } \\
\text { (Brilliant EverGlow) } \\
\text { Group } 2 \\
\text { (Brilliant NG) }_{\text {p-value }}^{\ddagger}\end{array}$ & $\begin{array}{l}1.35 \pm 1.49 \\
0.79 \pm 0.34 \\
0.312\end{array}$ & $\begin{array}{l}4.80 \pm 2.31 \\
2.03 \pm 0.95 \\
0.001\end{array}$ & $\begin{array}{l}2.68 \pm 0.99 \\
2.46 \pm 1.14 \\
0.588\end{array}$ & $\begin{array}{l}6.85 \pm 2.39 \\
2.90 \pm 0.76 \\
<0.001\end{array}$ & $\begin{array}{l}<0.001 \\
<0.001\end{array}$ & $\begin{array}{l}D>B>C>A \\
B, C, D>A \\
D>B\end{array}$ \\
\hline
\end{tabular}

Notes: ${ }^{\dagger} p$-value of Kruskal-Wallis ANOVA with post-hoc Conover test; ${ }^{\ddagger}$ Mann-Whitney U-test. 
on the degree of conversion, water sorption, solubility, and color stability. ${ }^{20}$

There was a significant amount of staining on both the composite restorative materials, which could be attributed to the capability of test solutions to soften resin-based restorative materials. However, maximum staining was seen with Brilliant EverGlow as compared to Brilliant NG. The variation in the filler content in both these composites was minimal by weight and volume, therefore, cannot be accounted for the difference in the staining propensity. ${ }^{21}$

Physico-chemical properties modulate the response of these restorative materials for extrinsic stains, with the rate of water sorption being an essential factor. ${ }^{22}$ Sensitivity to water sorption and solubility behavior, which are influenced by time of contact and $\mathrm{pH}$, seem to be closely related to the hydrophilic nature of the resin matrix. ${ }^{23,24}$ Also, micro-cracks, microvoids, or interfacial gaps found at the interface between matrix and fillers could induce stains. ${ }^{25}$ Therefore, if the filler particle size is not the factor for the difference in discoloration potential of Brilliant NG and Brilliant EverGlow, it could be due to the differences in water sorption characteristics of matrix or any such properties which needs further investigation.

Overall, Areca tea, Green tea, and Tulsi tea induced staining when compared to artificial saliva. Areca tea had the most detrimental effect in terms of staining potential, followed by Green tea and Tulsi tea at the end of the 60th day. This could be attributed to the tannin content in Areca nut $(11-27 \%)^{14}$, Green tea $(3-13 \%)^{26}$, Tulsi tea $(0.9$ to $2 \%) .{ }^{27}$ The role of immersion time could not be ignored in this study. The staining potential of these test solutions was almost similar at 30 days interval. Still, Areca tea specimens had higher staining potential than others at the end of 60 days, which could be attributed to high tannin content in Areca tea. Celik et al compared the color stability of different types and brands of resin composites before and after polymerization, and after one month of storage in water. They concluded that submicron-hybrid composites showed lower Delta E values compared to nano-hybrid composites. ${ }^{28}$ The results were not in agreement with the findings of our study, which could be due to the variation in staining solutions. Tan et al concluded that green tea, along with other solutions tested, had significant discoloration potential on new esthetic restoratives. ${ }^{29}$

Values of $\Delta \mathrm{E}^{*}$ less than 1 are not perceptible to the human eye, whereas values in the range of 1-3 represent color differences are perceptible experienced clinicians.
Values of $\Delta \mathrm{E}^{*}$ greater than or equal to 3.3 are visually perceptible and clinically unacceptable. ${ }^{17}$

Our study showed that Brilliant EverGlow specimens showed clinically perceptible changes $(\Delta \mathrm{E}>3.3)$ with Areca tea and Green tea after 60 days of immersion. For Brilliant NG, Areca tea, Green tea, and Tulsi tea after 60 days of immersion had $\Delta \mathrm{E}^{*}$ values in the range of $2-3$, suggesting that perceptible clinical changes were seen in this restorative material but to a lesser extent compared to Brilliant EverGlow. However, in the control solution, the least color change was observed for both materials, which was clinically perceptible for Brilliant EverGlow but less perceptible for Brilliant NG. Hence, we reject our null hypothesis as there was a significant difference in the staining potential of herbal tea preparations.

\section{Conclusion}

Within the limits of this study, it can be concluded that

- All novel herbal tea solutions tested exhibited staining potential, which increased over a period of time.

- Areca tea caused the highest discoloration among all three tea solutions.

- Universal nanohybrid composite (Brilliant NG) exhibited better color stability than Universal submicron hybrid composite (Brilliant EverGlow) in different solutions.

- Clinicians should be cautious in choosing the restorative material keeping in mind the staining propensity of the patient's dietary preferences.

\section{Disclosure}

The authors report no conflicts of interest for this work.

\section{References}

1. Ashok JS. Factors that influence the color stability of composite restorations. Int J Orofac Biol. 2017;1(1):1. doi:10.4103/JJOFB. IJOFB_5_16

2. Catelan A, Briso ALF, Sundfeld RH, Goiato MC, Dos Santos PH. Color stability of sealed composite resin restorative materials after ultraviolet artificial aging and immersion in staining solutions. $J$ Prosthet Dent. 2011;105(4):236-241. doi:10.1016/S0022-3913(11) 60038-3

3. Chacko SM, Thambi PT, Kuttan R, Nishigaki I. Beneficial effects of green tea: a literature review. Chin Med. 2010;5(1):13. doi:10.1186/ 1749-8546-5-13

4. Mak JCW. Potential role of green tea catechins in various disease therapies: progress and promise. Clin Exp Pharmacol Physiol. 2012;39(3):265-273. doi:10.1111/j.1440-1681.2012.05673.x

5. Cohen MM. Tulsi - Ocimum sanctum: a herb for all reasons. $J$ Ayurveda Integr Med. 2014;5(4):251-259. doi:10.4103/09759476.146554 
6. Keshava Bhat S, Sarpangala M, Ashwin D. Antilipidemic activity of areca nut, Areca catechu L.: a valuable herbal medicine. Int J Herb Med. 2017;5(1):35-38.

7. Albuquerque P, Nishida A, Francci CE. Is the color stability of resinbased composites affected by the shade of prefabricated composite resin veneer? Acta Sci Dent Sci. 2019;3(1):74-77.

8. Al Kheraif AA, Bin QSS, Ramakrishnaiah R, Ur Rehman I. Effect of different beverages on the color stability and degree of conversion of nano and micro hybrid composites. Dent Mater J. 2013;32(2):326331. doi:10.4012/dmj.2011-267

9. Koech RK, Wanyoko J, Wachira F. Antioxidant, antimicrobial and synergistic activities of tea polyphenols. Int J Infect Dis. 2014;21:98. doi:10.1016/j.ijid.2014.03.631

10. Drubi-Filho B, Garcia LD, Cruvinel DR, Sousa AB, Pires-de-Souza FD. Color stability of modern composites subjected to different periods of accelerated artificial aging. Braz Dent J. 2012;23(5):575580. doi:10.1590/S0103-64402012000500018

11. Topcu FT, Sahinkesen G, Yamanel K, Erdemir U, Oktay EA, Ersahan $\mathrm{S}$. Influence of different drinks on the colour stability of dental resin composites. Eur J Dent. 2009;03(01):50-56. doi:10.1055/s-00391697405

12. Bagheri R, Burrow MF, Tyas M. Influence of food-simulating solutions and surface finish on susceptibility to staining of aesthetic restorative materials. J Dent. 2005;33(5):389-398. doi:10.1016/j. jdent.2004.10.018

13. Nuaimi H, Ragab H. Effect of aggressive beverage on the color stability of different nano-hybrid resin-based composite. Eur J Gen Dent. 2014;3(3):190. doi:10.4103/2278-9626.141666

14. Malekipour MR, Sharafi A, Kazemi S, Khazaei S, Shirani F. Comparison of color stability of a composite resin in different color media. Dent Res J. 2012;9(4):441-446. doi:10.4103/1735-3327. 102781

15. Guler AU, Yilmaz F, Kulunk T, Guler E, Kurt S. Effects of different drinks on stainability of resin composite provisional restorative materials. J Prosthet Dent. 2005;94(2):118-124. doi:10.1016/j.prosdent. 2005.05.004

16. Mutlu-Sağesen L, Ergün G, Özkan Y, Semiz M. Color stability of a dental composite after immersion in various media. Dent Mater J. 2005;24(3):382-390. doi:10.4012/dmj.24.382

17. Khosravi M, Esmaeili B, Nikzad F, Khafri S. Color stability of nanofilled and microhybrid resin-based composites following exposure to chlorhexidine mouthrinses: an in vitro study. J Dent. 2016;13 (2):116-125
18. Soares-Geraldo D, Scaramucci T, Steagall-Jr W, Braga SRM, Sobral MAP. Interaction between staining and degradation of a composite resin in contact with colored foods. Braz Oral Res. 2011;25(4):369375. doi:10.1590/S1806-83242011000400015

19. Garcia PPNS, Neto ER, Dos Santos PA, Campos JÁDB, Dibb RGP. Influence of surface sealant on the translucency of composite resin: effect of immersion time and immersion media. Mater Res. 2008;11 (2):193-197. doi:10.1590/S1516-14392008000200014

20. Fonseca ASQS, Labruna Moreira AD, de Albuquerque PPAC, de Menezes LR, Pfeifer CS, Schneider LFJ. Effect of monomer type on the $\mathrm{C}=\mathrm{C}$ degree of conversion, water sorption and solubility, and color stability of model dental composites. Dent Mater. 2017;33 (4):394-401. doi:10.1016/j.dental.2017.01.010

21. Vichi A, Ferrari M, Davidson CL. Color and opacity variations in three different resin-based composite products after water aging. Dent Mater. 2004;20(6):530-534. doi:10.1016/j.dental.2002.11.001

22. Lu H, Roeder LB, Lei L, Powers JM. Effect of surface roughness on stain resistance of dental resin composites. J Esthet Restor Dent. 2005;17(2):102-108. doi:10.1111/j.1708-8240.2005.tb00094.x

23. Örtengren U, Andersson F, Elgh U, Terselius B, Karlsson S. Influence of $\mathrm{pH}$ and storage time on the sorption and solubility behaviour of three composite resin materials. $J$ Dent. 2001;29(1):35-41. doi:10.1016/S0300-5712(00)00055-5

24. Ortengren U. On composite resin materials. Degradation, erosion and possible adverse effects in dentists. Swed Dent J Suppl. 2000;141:161.

25. Ertaş E, Güler AU, Yücel AÇ, Köprülü H, Güler E. Color stability of resin composites after immersion in different drinks. Dent Mater J. 2006;25(2):371-376. doi:10.4012/dmj.25.371

26. Khasnabis J, Rai C, Roy A. Determination of tannin content by titrimetric method from different types of tea. J Chem Pharm Res. 2015;7(6):238-241.

27. Borah R, Biswas S. Tulsi (Ocimum sanctum), excellent source of phytochemicals. Int J Environ Agric Biotechnol. 2018;3(5):17321738. doi:10.22161/ijeab/3.5.21

28. Çelik EU, Aladağ A, Türkün LŞ, Yilmaz G. Color changes of dental resin composites before and after polymerization and storage in water. J Esthet Restor Dent. 2011;23(3):179-188. doi:10.1111/ j.1708-8240.2011.00421.x

29. Tan BL, Yap AUJ, Ma HNT, Chew J, Tan WJ. Effect of beverages on color and translucency of new tooth-colored restoratives. Oper Dent. 2015;40(2):E56-E65. doi:10.2341/149027-L

\section{Publish your work in this journal}

Clinical, Cosmetic and Investigational Dentistry is an international, peer-reviewed, open access, online journal focusing on the latest clinical and experimental research in dentistry with specific emphasis on cosmetic interventions. Innovative developments in dental materials, techniques and devices that improve outcomes and patient satisfaction and preference will be highlighted. The manuscript management system is completely online and includes a very quick and fair peer-review system, which is all easy to use. Visit http://www.dovepress.com/testimonials.php to read real quotes from published authors.

Submit your manuscript here: https://www.dovepress.com/clinical-cosmetic-and-investigational-dentistry-journal 